\title{
Relationship between the double burden of malnutrition and mental health in overweight and obese adult women
}

\author{
Mohammad Gholizadeh $^{1}$ (D), Leila Setayesh ${ }^{2}$ (D) Habib Yarizadeh $^{2}$, Atieh Mirzababaei ${ }^{2}$, Cain C. T. Clark ${ }^{3}$ \\ and Khadijeh Mirzaei ${ }^{2} *$ \\ ${ }^{1}$ Department of Cellular and Molecular Nutrition, School of Nutritional Sciences and Dietetics, Tebran University of Medical Sciences, Tehran, Iran \\ ${ }^{2}$ Department of Community Nutrition, School of Nutritional Sciences and Dietetics, Tehran University of Medical Sciences (TUMS), Tehran, Iran \\ ${ }^{3}$ Centre for Intelligent Healthcare, Coventry University, Coventry, CV1 5FB, U.K
}

(Received 21 July 2021 - Final revision received 22 December 2021 - Accepted 17 January 2022)

Journal of Nutritional Science (2022), vol. 11, e12, page 1 of 7

doi: $10.1017 /$ jns. 2022.7

Abstract

The co-existence of overweight or obesity with concurrent deficiency of one or more nutrients is referred to as double burden of malnutrition (DBM), and numerous mental health impairments have been associated with a variety of nutrient deficiencies. Although DBM is relevant for several health outcomes, the ubiquitous involvement of vitamin D across multiple systems and tissues suggests D insufficiency as a viable target for nutritional modification. The present study aimed to evaluate the contribution of DBM and mental health among adult women. Study participants included 300 women, aged $18-59$ years, who presented to one of the 25 health centres in Tehran. Participants with a body mass index (BMI) of greater than $25 \mathrm{~kg} / \mathrm{m}^{2}$ and a plasma concentration of 25-hydroxy vitamin D [25(OH)D] of $>20 \mathrm{ng} / \mathrm{ml}$ were considered to have DBM. The 147-item food frequency questionnaire was used to estimate their dietary intake. Mental health status was assessed using the depression, anxiety and stress scales-21 (DASS-21). The mean \pm standard deviation age, weight and BMI of the participants were $36 \cdot 49 \pm 8 \cdot 38,80 \cdot 89 \pm 12 \cdot 45 \mathrm{~kg}$ and $31 \cdot 04 \pm 4 \cdot 31 \mathrm{~kg} / \mathrm{m}^{2}$, respectively. DBM was significantly associated with stress, after adjusting for potential confounders, including age, energy and marital status in model 1 (OR $=1 \cdot 28$, $95 \%$ confidence interval (CI) $1 \cdot 00,1 \cdot 65, P<0 \cdot 04) v$. the crude model (OR $=1 \cdot 22$; $95 \%$ CI $0 \cdot 96,1 \cdot 55, P=0 \cdot 09)$. No significant association was seen among DBM and DASS-21 outcomes. In this cross-sectional study, stress and DBM were significantly associated. While vitamin D insufficiency was associated with mental health and obesity in opposing directions. Elucidation of whether vitamin D supplementation can improve mental health impairments requires further evaluation.

Key words: Anxiety: Depression: Double burden of malnutrition: Stress

\section{Introduction}

The continued rise in overweight and obesity remains a global health concern. In particular, the increases and consequent adverse health effects widely recognised among developing countries are introducing a significant health challenge ${ }^{(1)}$. Furthermore, the emergence of double burden of malnutrition (DBM), the co-existence of caloric overconsumption with essential nutrient insufficiency, has been reported as increasingly prevalent in developing countries in comparison to developed countries ${ }^{(2,3)}$. While contributors to this phenomenon include increased urbanisation, alteration of dietary patterns and lifestyle ${ }^{(4)}$, some nutrients are more likely to be implicated in adverse health effects.

The physiologic effects of DBM are well recognised. However, a comprehensive understanding of modifiable health outcomes requires an understanding of the psychological effects of DBM. Indeed, an association between obesity and a number of mental health impairments across the life course has been reported ${ }^{(5,6)}$.

Given that poor mental health affects more than 300 million people, of all ages, the additive effect of the obesity epidemic and mental health impairments could have a profound effect

Abbreviations: BMI: body mass index; DBM: double burden of malnutrition; DBP: vitamin D binding protein; 25(OH)D: 25-hydroxy vitamin D

* Corresponding author: Khadijeh Mirzaei, email mirzaei_kh@tums.ac.ir

(C) The Author(s), 2022. Published by Cambridge University Press on behalf of The Nutrition Society. This is an Open Access article, distributed under the terms of the Creative Commons Attribution licence (https://creativecommons.org/licenses/by/4.0/), which permits unrestricted re-use, distribution, and reproduction in any medium, provided the original work is properly cited. 
on mortality in the ensuing decade(s). Indeed, a bidirectional link between obesity and mental health has been suggested ${ }^{(7)}$, with obesity increasing the risk of depression incidence, and a suggested mechanistic role ${ }^{(8)}$ of inadequate essential nutrient intake as a moderator ${ }^{(9,10)}$. Suboptimal nutrient intake, including cobalamin, folic acid, niacin and ascorbic acid, zinc, iron and selenium, has been associated with depression ${ }^{(11)}$. However, the ubiquitous involvement of vitamin D in neurocognition and obesity-related disorders offers a viable area of investigation as a modifiable intervention ${ }^{(12,13)}$. Many studies have reported that changes in a plasma concentration of 25-hydroxy vitamin D [25(OH)D] and fatty mass were inversely and significantly associated; moreover, obese subjects tended to show low absorption of vitamin $\mathrm{D}^{(14,15)}$. Furthermore, vitamin D absorbs by complex mechanisms; for instance, in the gastrointestinal tract (GIT), vitamin D is involved in lipid metabolism and diffuses in chylomicrons, which facilitates transportation in the liver ${ }^{(16)}$. Also, obese subjects demonstrate a low concentration of plasma $25(\mathrm{OH}) \mathrm{D}$, as well as low 25(OH)D and obesity related to high waist circumference, high body mass index (BMI), hypertension, insulin resistance, glycaemic profile, impaired lipids and other cardiometabolic disorders ${ }^{(17,18)}$. Several explanations have been offered to explain the reduced concentration of $25(\mathrm{OH}) \mathrm{D}$, including low sun exposure because of a sedentary lifestyle, the sequestration of $25(\mathrm{OH}) \mathrm{D}$ in adipose tissue, and dilution of ingested $25(\mathrm{OH}) \mathrm{D}$ and synthesis in large fat of obese patients ${ }^{(19)}$. Furthermore, BsmI and ApaI VDR genes in overweight and obese women are reported to account for polymorphism and seem to affect BMI. Also, adipose stores have a haemostatic role in inflammation and innate immunity in human individuals by modulating of toll-like receptors and nuclear factor-kappaB (NF-kB) pathways ${ }^{(20-22)}$.

Observational studies have suggested that vitamin D deficiency may be related to depression and increased suicide $^{(23-26)}$. However, there is a distinct dearth of studies about the association between DBM and mental health. Therefore, in this cross-sectional study, we assessed the association between DBM and mental health, including depression, anxiety and stress, in Iranian women with obesity, with a focus on vitamin $\mathrm{D}$ as a potential moderator.

\section{Method}

\section{Study design}

A cohort of 300 women with obesity and overweight, aged 18-59 years, participated in the present study. Women were randomly selected from those presenting to twenty-five health centres in Tehran. The sampling method was achieved by multistage cluster randomisation among all the Tehran regions. The participants were included among twenty clusters from 2017 to 2019.

Inclusion criteria were aged 18-59 years; no current weight loss programme; no use of weight loss supplements. Participants with a history of type 2 diabetes, cardiovascular diseases, polycystic ovary syndromes, stroke, non-alcoholic fatty liver disease, inflammatory disease, hypertension, cancer, thyroid diseases, or who were currently pregnant, were excluded because of possible changes in diet. In addition, women reporting intake energy lower or higher than 800 $4200 \mathrm{kcal}$, respectively, were excluded.

The present study was conducted according to the guidelines in the Declaration of Helsinki and all procedures involving human subjects were approved by the ethics committee of the Tehran University of Medical Science (IR.TUMS.VCR. REC.1398.819). Written informed consent was obtained from all subjects prior to participation.

\section{Anthropometric assessments}

The individuals wore light clothing and were unshod for the measurement of weight and height. All measurements were assessed by a trained technician. The waist circumference ${ }^{(27)}$ was measured using a non-elastic tape, to the nearest $0 \cdot 1$ $\mathrm{cm}$, according to standard protocols. In addition, hip circumference was determined as the largest part of the hip, over light clothing. BMI was calculated based on Quetelet's index ${ }^{(28)}$. According to WHO guidelines, the individuals were classified as underweight (BMI: $<18.50 \mathrm{~kg} / \mathrm{m}^{2}$ ), normal weight $(18 \cdot 50$ $\left.24.99 \mathrm{~kg} / \mathrm{m}^{2}\right)$, overweight $\left(25.0-29.9 \mathrm{~kg} / \mathrm{m}^{2}\right)$ and obesity $\left(\geq 30 \cdot 0 \mathrm{~kg} / \mathrm{m}^{2}\right)$.

Complete body composition analysis. The body composition of all participants was analysed using a body analyser device (model BC-418, MA-Tanita, product by the UK). This instrument measured the body composition, including body fat mass, fat-free mass (FFM) ${ }^{(29)}$ and visceral fat area (VFA), using bioelectrical impedance analysis ${ }^{(30)}$. According to the manufacturer's instructions, after shoes, coats and sweaters had been removed, subjects were required to stand on the balance scale, in bare feet, and hold the handles of the machine. The measurements took approximately $20 \mathrm{~s}$, and the output was printed.

\section{Dietary intake assessment}

The individual diet intake was assessed by a 147-item food frequency questionnaire that was previously validated ${ }^{(31)}$. The data documented in household measures and serving size were changed to grams and millimetres. The nutritionist IV (First Data Bank, San Bruno, CA) food analyser was used for analysing dietary intake.

\section{Blood sampling and biochemical parameters}

At first, a 10-ml blood sample was drawn after 8-12 h of fasting, and the serum was centrifuged, and isolated and stored at $-80^{\circ} \mathrm{C}$. All data were evaluated by the Endocrinology \& Metabolism Research Institute (EMRI) Bionanotechnology laboratory of the Tehran University of Medical Science. Serum fasting glucose assessment was made using glucose oxidase-phenol 4-amino antipyrine peroxidase (GOD-PAP) (colorimetric method), while triacylglycerol (TG) and total cholesterol $^{(20)}$ (CHOL) were measured using glycerol-3- 
phosphate oxidase-phenol 4-amino antipyrine peroxidase (GPO-PAP) and enzymatic endpoint, respectively. Also, lowdensity lipoprotein (LDL) and high-density lipoprotein (HDL) cholesterol were measured by direct enzymatic clearance assay. All laboratory assessments were performed using Seven Randox Laboratories kits (Random Laboratories Ltd., Ardmore, UK).

The concentration of $25(\mathrm{OH}) \mathrm{D}$ in individuals was assessed using an immunoassay immunodiagnostic system (IDS) kit. Finally, serum concentrations of $25(\mathrm{OH}) \mathrm{D}$ between 20 and $30 \mathrm{ng} / \mathrm{ml}$ and less than $20 \mathrm{ng} / \mathrm{ml}$ were considered as insufficiency and deficiency, respectively ${ }^{(32-35)}$.

Calculation of the DBM and mental disorders. DBM was assessed by calculating BMI (based on Quetelet's index ${ }^{(28)}$ ) and vitamin D levels. Accordingly, BMI greater than $25 \mathrm{~kg} / \mathrm{m}^{2}$ along with plasma concentrations of vitamin D lower than 20 $\mathrm{ng} / \mathrm{ml}(25(\mathrm{OH}) \mathrm{D}<20 \mathrm{ng} / \mathrm{ml})$ was considered DBM.

Depression, anxiety and stress scale questionnaire. Mental health status was calculated using the depression, anxiety and stress scales ${ }^{(36)}$, which is a 42 -item self-report scale that generates three scale scores, with each scale consisting of 14 questions scored from 0 to 3 . Where $0=\operatorname{did}$ not apply to me at all and $3=$ applied to me very much, or most of the time, with a total possible scale range for each scale of $0-42^{(37,38)}$.

\section{Statistical analysis}

Normality distribution was tested using a KolmogorovSmirnov test; for data that were not normally distributed, and could not be transformed appropriately for normal distribution, $z$-scores were used. Data on quantitative characteristics were reported as the mean $\pm \mathrm{SD}$, and data on qualitative characteristics were expressed as a percentage. $\chi^{2}$ analysis was performed for detection confounders and to recognise mental health disorders. One-way analysis of variance (ANOVA) and Tukey post hoc tests, where appropriate, were used for a comparison of variables. The logistic regression was performed to discern the relationship between vitamin $\mathrm{D}$ deficiency in overweight and people with obesity by mental disorders. An initial model (0) was created and included only vitamin $\mathrm{D}$ deficiency (using 20 as a cut point), and a secondary model (1) included vitamin D deficiency and mental health status, in addition to age, energy and marital status. All statistical analysis was performed using IBM SPSS for Windows version 23 (SPSS Inc, Chicago, IL, USA), and a $P$ value of $<0 \cdot 05$ was, a priori, considered as statistically significant.

\section{Results}

Descriptive statistics are represented in Table 1. Accordingly, the mean age and BMI of participants were $36.49 \pm 8.38$ years and $31.04 \pm 4.3 \mathrm{~kg} / \mathrm{m}^{2}$, respectively.

The number of people in each category and characteristics are shown in Table 2. Based on Table 2, 305 individuals
Table 1. Baseline characteristic of participants (mean \pm SD)

\begin{tabular}{|c|c|c|}
\hline Name $\quad(n)$ & Mean & SD \\
\hline $\mathrm{Age}^{\mathrm{a}}$ & 36.47 & 8.40 \\
\hline Overweight $^{\mathrm{b}}(n$ 137) & 35.21 & 7.97 \\
\hline Obese ( $n$ 161) & 37.54 & 8.64 \\
\hline Weight (total) & 80.81 & 12.39 \\
\hline Overweight (n 138) & 72.15 & 6.37 \\
\hline Obese $(n$ 161) & 88.24 & 11.44 \\
\hline BMI $\left(\mathbf{k g} / \mathrm{m}^{2}\right)$ & 31.04 & 4.31 \\
\hline Overweight ( $n$ 139) & 27.57 & 1.51 \\
\hline Obese $(n 162)$ & 34.02 & 3.67 \\
\hline \multicolumn{3}{|c|}{ Body composition } \\
\hline BFM & 34.04 & 8.69 \\
\hline Overweight (n 139) & 27.42 & 3.66 \\
\hline Obese $(n$ 162) & 39.72 & 7.68 \\
\hline WHR & 1.23 & 5.24 \\
\hline Overweight (n 139) & 0.90 & 0.04 \\
\hline Obese $(n$ 162) & 1.51 & 7.15 \\
\hline WC & 99.01 & 10.05 \\
\hline Overweight ( $n$ 139) & 91.48 & 5.53 \\
\hline Obese $(n 162)$ & 105.48 & 8.42 \\
\hline Visceral fat area $\left(\mathrm{cm}^{2}\right)$ & 168.30 & 103.11 \\
\hline Overweight ( $n$ 139) & 133.87 & 23.94 \\
\hline Obese $(n 162)$ & 197.84 & 131.97 \\
\hline
\end{tabular}

Blood parameters and blood pressure

\begin{tabular}{|c|c|c|}
\hline CHOL (g/dl) & 185.29 & 35.85 \\
\hline Overweight ( $n$ 126) & 177.47 & 31.63 \\
\hline Obese $(n$ 128) & 192.98 & 38.14 \\
\hline$T G(g / d l)$ & 122.52 & 69.38 \\
\hline Overweight ( $n$ 126) & 104.07 & 47.63 \\
\hline Obese $(n 128)$ & 140.67 & 81.77 \\
\hline HDL (mg/dl) & 46.63 & 10.80 \\
\hline Overweight ( $n$ 126) & 47.55 & 10.15 \\
\hline Obese $(n 128)$ & 45.72 & 11.38 \\
\hline LDL (mg/dl) & 95.53 & 24.07 \\
\hline Overweight (n 126) & 92.80 & 22.44 \\
\hline Obese $(n$ 128) & 98.21 & 25.38 \\
\hline SBP (mm Hg) & 111.75 & 13.69 \\
\hline Overweight ( $n$ 133) & 108.88 & 12.66 \\
\hline Obese $(n$ 152) & 114.25 & 14.10 \\
\hline DBP (mm Hg) & 77.88 & 9.60 \\
\hline Overweight ( $n$ 133) & 75.86 & 8.59 \\
\hline Obese ( $n$ 152) & 79.65 & 10.15 \\
\hline $25(\mathrm{OH}) \mathrm{D}(\mathrm{ng} / \mathrm{ml})$ & 66.74 & 47.00 \\
\hline Overweight ( $n$ 109) & 69.23 & 46.74 \\
\hline Obese $(n$ 124) & 64.54 & 47.32 \\
\hline
\end{tabular}

${ }^{a}$ table items indicate the variables in overweight and obese in totals as well as ${ }^{b}$ in overweight and obese participants separately. BMI, body mass index; BFM, body fat mass; FFM, fat-free mass, WHR, waist hip ratio; WC, waist circumference; TG, triacylglycerol; HDL, high-density lipoprotein; LDL, low-density lipoprotein; SBP, systolic blood pressure; DBP, diastolic blood pressure.

were initially enrolled in the present study; however, after exclusion based on our inclusion/exclusion criteria, 231 individuals remained for analysis. In Table 2, we show that there were no significant differences in variables between groups.

Table 3 illustrates the mean \pm SD of characteristics of variables in four categories, showing that there are significant body composition differences, including weight, BMI, waist circumference $^{(27)}$, fat-free mass ${ }^{(29)}$, VFA, TG $(P<0 \cdot 0001)$ and $\mathrm{CHOL}(P<0 \cdot 05)$, and diastolic blood pressure $(P<0 \cdot 02)$.

Table 4 shows the evaluation relationship between mental health and DBM, where there were no observed significant 
Table 2. Association between mental health and sample sizes in each confounder

\begin{tabular}{|c|c|c|c|c|c|c|c|c|c|c|}
\hline \multirow[b]{2}{*}{ Variables } & & \multicolumn{3}{|c|}{ Anxiety (n 282) } & \multicolumn{3}{|c|}{ Stress ( $n$ 282) } & \multicolumn{3}{|c|}{ Depression ( $n$ 282) } \\
\hline & & cat1 $(n)$ & cat2 $(n)$ & $P$ & cat1 $(n)$ & cat2 $(n)$ & $P$ & cat1 $(n)$ & cat2 $(n)$ & $P$ \\
\hline \multirow[t]{7}{*}{ Education } & Illiterate & 1 & 2 & 0.57 & 1 & 2 & 0.34 & 1 & 2 & 0.48 \\
\hline & Primary education & 3 & 10 & & 5 & 8 & & 3 & 10 & \\
\hline & Intermediate Education & 6 & 12 & & 3 & 13 & & 5 & 13 & \\
\hline & High school education & 5 & 3 & & 6 & 1 & & 5 & 3 & \\
\hline & Diploma & 33 & 51 & & 44 & 40 & & 44 & 40 & \\
\hline & Postgraduate education & 13 & 13 & & 12 & 14 & & 13 & 13 & \\
\hline & Bachelor's degree and higher & 52 & 78 & & 65 & 65 & & 78 & 52 & \\
\hline \multirow[t]{6}{*}{ Job } & Housekeeper & 70 & 101 & 0.51 & 86 & 85 & 0.39 & 83 & 88 & 0.19 \\
\hline & Labour & 2 & 2 & & 2 & 2 & & 2 & 2 & \\
\hline & Management employee & 21 & 25 & & 8 & 28 & & 25 & 21 & \\
\hline & Non-managerial employee & 12 & 22 & & 22 & 12 & & 25 & 9 & \\
\hline & Household jobs & 4 & 5 & & 8 & 9 & & 4 & 5 & \\
\hline & University student & 5 & 13 & & 8 & 12 & & 10 & 8 & \\
\hline \multirow[t]{5}{*}{ Marriage } & Married & 89 & 130 & 0.29 & 106 & 113 & 0.04 & 113 & 106 & 0.14 \\
\hline & Single & 23 & 31 & & 30 & 24 & & 34 & 20 & \\
\hline & Away from spouse more than 6 month & 0 & 2 & & 0 & 2 & & 0 & 2 & \\
\hline & Dead spouse & 1 & 1 & & 2 & 0 & & 1 & 2 & \\
\hline & Divorce & 0 & 5 & & 0 & 5 & & 0 & 4 & \\
\hline \multirow[t]{4}{*}{ Monthly salary } & Low & 5 & 5 & 0.26 & 2 & 4 & 0.69 & 2 & 4 & 0.49 \\
\hline & Medium & 4 & 8 & & 7 & 6 & & 6 & 7 & \\
\hline & Good & 36 & 76 & & 43 & 74 & & 42 & 71 & \\
\hline & Excellent & 53 & 95 & & 61 & 87 & & 68 & 82 & \\
\hline \multirow[t]{4}{*}{ Housing status } & Owner & 74 & 97 & 0.17 & 92 & 79 & 0.11 & 92 & 79 & 0.64 \\
\hline & Tenant & 38 & 63 & & 43 & 58 & & 51 & 50 & \\
\hline & Relatives' house & 2 & 5 & & 2 & 4 & & 3 & 3 & \\
\hline & Organisation house & 2 & 1 & & 2 & 2 & & 2 & 2 & \\
\hline \multirow[t]{3}{*}{ Economic status } & Low & 31 & 33 & 0.42 & 31 & 35 & 0.53 & 32 & 34 & 0.26 \\
\hline & Medium & 49 & 88 & & 61 & 82 & & 66 & 77 & \\
\hline & Good & 40 & 41 & & 41 & 32 & & 41 & 32 & \\
\hline \multirow[t]{2}{*}{ Smoking } & Yes & 7 & 9 & 0.78 & 9 & 7 & 0.54 & 7 & 9 & 0.47 \\
\hline & No & 107 & 159 & & 129 & 137 & & 141 & 125 & \\
\hline
\end{tabular}

$\chi^{2}$ test for recognising confounders into categories. cat1: healthy mental; cat2: unhealthy mental.

associations between anxiety and depression after adjusting potential confounders including age, energy and marital status in model $1(0.26,0.74) v$. the crude model $(0.35,0.75)$, respectively. However, there was a significant relationship between stress and DBM after adjusting age, energy and marital status in model $1(0 \cdot 04) v$. the crude model $(0 \cdot 09)$.

Table 3. Characteristics of variables in four categories

\begin{tabular}{|c|c|c|c|c|c|c|c|c|c|}
\hline Variable & Q1 & & Q2 & & Q3 & & Q4 & & $P$ value \\
\hline & Mean (77) & SD & Mean (31) & SD & Mean (82) & SD & Mean & SD & \\
\hline Age (years) & $35 \cdot 48$ & 8.02 & $33 \cdot 70$ & 8.15 & $37 \cdot 60$ & 8.92 & 37.04 & 7.98 & 0.11 \\
\hline Weight (Kg) & $71 \cdot 85$ & 5.32 & $74 \cdot 37$ & 8.19 & $89 \cdot 22$ & 11.31 & 87.05 & 11.35 & $<0.001$ \\
\hline $\mathrm{BMI}\left(\mathrm{kg} / \mathrm{m}^{2}\right)$ & $27 \cdot 51$ & 1.47 & $27 \cdot 79$ & 1.44 & $34 \cdot 28$ & 3.85 & 33.76 & 3.64 & $<0.001$ \\
\hline \multicolumn{10}{|c|}{ Body composition analysis } \\
\hline Body fat mass & $27 \cdot 38$ & 3.38 & 28.58 & 4.40 & $40 \cdot 17$ & & 39.29 & 7.19 & $<0.001$ \\
\hline FFM (\%) & 44.39 & 4.13 & 45.46 & 5.65 & $49 \cdot 17$ & 5.59 & 48.43 & 5.44 & $<0.001$ \\
\hline WHR & 0.90 & 0.04 & 0.91 & 0.04 & 2.05 & 9.99 & 0.96 & 0.04 & 0.59 \\
\hline WC & 91.46 & 5.05 & 93.34 & 6.72 & $105 \cdot 74$ & 8.29 & $105 \cdot 66$ & 8.63 & $<0.001$ \\
\hline $\operatorname{VFA}\left(\mathrm{cm}^{2}\right)$ & $133 \cdot 71$ & 22.37 & 141.54 & 28.48 & $206 \cdot 72$ & 182.70 & 189.08 & 29.73 & $<0.001$ \\
\hline \multicolumn{10}{|c|}{ Blood parameters } \\
\hline Cholesterol (g/dl) & 175.98 & 29.07 & $184 \cdot 34$ & 33.00 & $192 \cdot 87$ & 41.93 & $188 \cdot 48$ & 37.46 & 0.05 \\
\hline TG (g/dl) & 99.64 & 46.63 & $103 \cdot 10$ & 42.22 & $145 \cdot 46$ & 92.03 & $124 \cdot 60$ & 74.41 & $<0.001$ \\
\hline LDL (mg/dl) & 91.60 & 19.98 & 93.06 & 26.43 & 95.68 & 25.03 & $95 \cdot 11$ & 26.00 & 0.77 \\
\hline $\mathrm{HDL}(\mathrm{mg} / \mathrm{dl})$ & 47.42 & 10.11 & $47 \cdot 20$ & 11.16 & 44.69 & 11.23 & 47.00 & 12.82 & 0.51 \\
\hline $\mathrm{SBP}(\mathrm{mm} \mathrm{Hg})$ & $110 \cdot 20$ & 11.74 & $108 \cdot 62$ & 13.85 & 113.42 & 15.47 & 114.92 & 13.50 & 0.12 \\
\hline $\mathrm{DBP}(\mathrm{mm} \mathrm{Hg})$ & $77 \cdot 23$ & 8.59 & 74.40 & 8.46 & 78.60 & 9.97 & 81.07 & 11.41 & 0.02 \\
\hline
\end{tabular}

BMI; body fat mass, VFA; visceral fat area; FFM, fat-free mass; WHR, waist hip ratio; WC, waist circumference; TG, triacylglycerol; HDL, high-density lipoprotein; LDL, low-density lipoprotein; SBP, systolic blood pressure; DBP, diastolic blood pressure. Q1, overweight without D deficiency; Q2, overweight with D deficiency; Q3, people with obesity without D deficiency; Q4, people with obesity D deficiency.

The ANOVA test was performed for the potential effect of confounders in each quartile. 
Table 4. Comparison association between DBM and mental health before and after adjusting potential confounders

\begin{tabular}{|c|c|c|c|c|c|}
\hline Variables & Q1 & Q2 & Q3 & Q4 & $P$-trend \\
\hline \multicolumn{6}{|c|}{ Anxiety } \\
\hline Model 0 & 1 & $1.12(0.48-2.58)$ & $1.97(1.00-3.86)$ & $1.01(0.46-2.21)$ & 0.35 \\
\hline Model 1 & 1 & $1.32(0.55-3.19)$ & $1.87(0.93-3.76)$ & $1.21(0.54-2.73)$ & 0.26 \\
\hline \multicolumn{6}{|c|}{ Stress } \\
\hline Model 0 & 1 & $1.45(0.63-3.34)$ & $1.54(0.80-2.95)$ & $1.84(0.83-4.05)$ & 0.09 \\
\hline Model 1 & 1 & $1.38(0.58-3.29)$ & $1.53(0.78-3.02)$ & $2.29(1.00-5.22)$ & $<0.04$ \\
\hline \multicolumn{6}{|c|}{ Depression } \\
\hline Model 0 & 1 & $0.79(0.34-1.84)$ & $1.05(0.55-2.01)$ & $1.08(0.49-2.35)$ & 0.75 \\
\hline Model 1 & 1 & $0.72(0.30-1.74)$ & $0.98(0.50-1.93)$ & $1.13(0.50-2.54)$ & 0.74 \\
\hline
\end{tabular}

Model 0: crude model; Model 1: adjusted for age, energy, marriage status.

\section{Discussion}

This novel investigation sought to identify the role of vitamin $\mathrm{D}$ as a moderator in the association between DBM and mental health and, to our knowledge, was the first conducted in Iranian women. In the present study, we considered the presence of overweight and obesity with the deficiency of vitamin $\mathrm{D}$ as a DBM. Many previous studies have demonstrated a significant association between vitamin $\mathrm{D}$ and depression. Moreover, vitamin D levels have been shown to be impeded due to air pollution in industrial cities, low intake in some countries, use of cosmetics, sunlight cream, some clothing because of religion and age because of decreasing synthesis by skin and absorption by the intestine. Iranian women are reported to have an increased susceptibility to vitamin D deficiency, either by type of clothing or low consumption of dairy. In the present study, we observed a significant relationship between DBM and stress; in addition, we observed significant differences between four categories in BMI, weight and body composition items including waist circumference ${ }^{(27)}$, fat-free mass ${ }^{(29)}$, VFA and lipid profiles, such as TG and CHOL, and diastolic blood pressure.

Vitamin D is an important fat-soluble vitamin that is immune-modulating and can inhibit many communicable diseases including, heart disease, multiple sclerosis, rheumatoid arthritis and type 1 diabetes. Indeed, the deficiency of vitamin $\mathrm{D}$ is associated with many disorders, including skeletal abnormalities, delayed growth in children, osteoporosis and osteopenia, reduction of calcium and phosphorus absorption in the intestine. The main sources of vitamin D are exposure of skin to sunlight and consumption of foods containing vitamin $\mathrm{D}$, such as dairy. Vitamin D deficiency is common in Iranian people; indeed, based on a meta-analysis that was performed in Iranian people, $45.64 \%$ of men and $61.90 \%$ of women showed vitamin D deficiency. Moreover, the geographical location, type of clothing, poor diet, expensive dairy costs and skin colours are posited to modulate this deficiency ${ }^{(39-43)}$.

$25(\mathrm{OH}) \mathrm{D}$ levels, either by diet or synthesised by skin, are highly dependent on vitamin $\mathrm{D}$ binding protein (DBP), also a high level of $25(\mathrm{OH}) \mathrm{D}$, as well as $1 \cdot 25(\mathrm{OH}) \mathrm{D}$, appear on DBP (more than $80 \%$ ), whereas DBP is responsible for 25 $(\mathrm{OH}) \mathrm{D}$ plasma concentrations. Some studies have reported a positive association between BMI and DBP plasma concentration, and many studies have reported that the $25(\mathrm{OH}) \mathrm{D}$ concentrations in overweight and obese people may be reduced significantly. Because of this evident correlation between vitamin D status and DBP in obese individuals, we considered the level of plasma vitamin D status between 20 and $30 \mathrm{ng} / \mathrm{l}$ and less than $20 \mathrm{ng} / \mathrm{ml}$ to represent insufficiency and deficiency, respectively $(34,35,44,45)$.

Currently, obesity and overweight represent significant health issues associated with inflammatory status. Obesity is implicated in a mutation in the leptin/melanocortin pathway in the central nervous system, which plays a role in regulating body energy haemostasis. Moreover, obesity related to many brain disorders and psychopathology conditions, including eating and mood disorders ${ }^{(46-48)}$, plays an important role in depression conditions ${ }^{(38,49-51)}$, where high BMI has been associated with mood disorders (OR 1.23) and major depression (OR 1.27). In addition, evidence suggests a significant relationship between high BMI and anxiety disorders, such as post-traumatic stress disorders (OR 2.64) ${ }^{(52)}$. Anglin et al. performed a systematic review and meta-analysis on one case control, three cohorts, and ten cross-sectional studies and reported a significant relationship between vitamin D deficiency and depression ${ }^{(10)}$.

Concordant with our findings, Mousa et al. carried out a study on sixty-three overweight participants (thirty-nine males and twenty-four females), with a mean age $=31.3 \pm$ $8 \cdot 5$, along with vitamin D deficiency $[25(\mathrm{OH}) \mathrm{D}<20 \mathrm{ng} / \mathrm{l}]$ and BMI $25 \mathrm{~kg} / \mathrm{m}^{2}$, without clinical depression, consumed a bolus oral dosage of $100000 \mathrm{IU}$, followed by $4000 \mathrm{IU}$ daily cholecalciferol for 16 weeks. Subsequently, the authors observed an increasing concentration of plasma vitamin $\mathrm{D}$, and reported that vitamin D deficiency was not associated with depression, has therefore not warranted for reducing depression symptoms ${ }^{(53)}$.

In contrast with our finding, Schaad et al., in 18-67 years old males and females, found a significant relationship between vitamin $\mathrm{D}$ deficiency and depression. However, the number of males ( $n$ 9799) was notably more than the number of female counterparts ( $n$ 1121), which likely biased the findings ${ }^{(54)}$. Similarly, Umhau reported a significant correlation between suicide and vitamin D deficiency among active-duty military personnel, where the number of males ( $n$ 467) was significantly greater than the number of females $(n 19)^{(26)}$. Nevertheless, tentative conclusions from the literature suggest that the correlation between depression and vitamin $\mathrm{D}$ deficiency may be greater in males $v$. females. 
Although we present a novel addition to the literature, where we assessed DBM and mental health in Iranian women, there were several limitations that should be noted. First, we did not assess normal-weight participants with vitamin D deficiency, this precluded a comparison between normal weight $v$. overweight/obesity and represents a sensible avenue for further research. Moreover, although we focused on women, who appear to be relatively underrepresented in comparable research, future studies should be designed considering an equitable split in sex.

\section{Conclusion}

In this cohort study, we demonstrated that stress and DBM were significantly associated; however, the directionality of the relationship remains unclear. Vitamin D insufficiency is associated with mental health and obesity in opposing directions, and whether vitamin D supplementation can improve mental health impairments requires further evaluation.

\section{Acknowledgments}

We are grateful to our co-workers. The present study was supported by the Tehran University of Medical Sciences (TUMS), Tehran, Iran (Grant IDs: 97-03-161-41144 and 97-03-161-41155).

The project is funded by the Tehran University of Medical Sciences.

K.M, M.G., L.S. and A.M designed and constructed the research, wrote paper and had primary responsibility for the final content. M.G., L.S. and H.Y. carried out the statistical analysis. All authors have read and approved the final manuscript and agree to be accountable for all aspects of the work.

M.G., L.S., H.Y., A.M., C.C.T.C. and K.M. declare that there is no conflict of interest.

\section{References}

1. Ng M, Fleming T, Robinson M, et al. (2014) Global, regional, and national prevalence of overweight and obesity in children and adults during 1980-2013: a systematic analysis for the Global Burden of Disease Study 2013. The Lancet 384, 766-781.

2. Oddo VM, Rah JH, Semba RD, et al. (2012) Predictors of maternal and child double burden of malnutrition in rural Indonesia and Bangladesh. Am J Clin Nutr 95, 951-958.

3. Wells JC, Sawaya AL, Wibaek R, et al. (2020) The double burden of malnutrition: aetiological pathways and consequences for health. The Lancet 395, 75-88.

4. Wojcicki JM (2014) The double burden household in sub-Saharan Africa: maternal overweight and obesity and childhood undernutrition from the year 2000: results from World Health Organization Data (WHO) and Demographic Health Surveys (DHS). BMC Public Health 14, 1124.

5. Simon GE, Von Korff M, Saunders K, et al. (2006) Association between obesity and psychiatric disorders in the US adult population. Arch Gen Psychiatry 63, 824-830.

6. Markowitz S, Friedman MA \& Arent SM (2008) Understanding the relation between obesity and depression: causal mechanisms and implications for treatment. Clin Psychol Sci Pract 15, 1-20.
7. De Wit L, Luppino F, van Straten A, et al. (2010) Depression and obesity: a meta-analysis of community-based studies. Psycbiatry Res 178, 230-235.

8. Luppino FS, de Wit LM, Bouvy PF, et al. (2010) Overweight, obesity, and depression: a systematic review and meta-analysis of longitudinal studies. Arch Gen Psychiatry 67, 220-229.

9. Akbaraly TN, Brunner EJ, Ferrie JE, et al. (2009) Dietary pattern and depressive symptoms in middle age. Br J Psychiatry 195, 408-413.

10. Anglin RE, Samaan Z, Walter SD, et al. (2013) Vitamin D deficiency and depression in adults: systematic review and meta-analysis. Br J Psychiatry 202, 100-107.

11. Bodnar LM \& Wisner KL (2005) Nutrition and depression: implications for improving mental health among childbearing-aged women. Biol Psycbiatry 58, 679-685.

12. Armstrong D, Meenagh G, Bickle I, et al. (2007) Vitamin D deficiency is associated with anxiety and depression in fibromyalgia. Clin Rheumatol 26, 551-554.

13. Jorde R, Sneve M, Figenschau Y, et al. (2008) Effects of vitamin D supplementation on symptoms of depression in overweight and obese subjects: randomized double blind trial. J Intern Med 264, 599-609.

14. Wortsman J, Matsuoka LY, Chen TC, et al. (2000) Decreased bioavailability of vitamin D in obesity. Am J Clin Nutr 72, 690-693.

15. Vanlint S (2013) Vitamin D and obesity. Nutrients 5, 949-956.

16. Maurya VK \& Aggarwal M (2017) Factors influencing the absorption of vitamin D in GIT: an overview. J Food Sci Tecbnol 54, 3753-3765.

17. Renzaho AM, Halliday JA \& Nowson C (2011) Vitamin D, obesity, and obesity-related chronic disease among ethnic minorities: a systematic review. Nutrition 27, 868-879.

18. Pourshahidi LK (2015) Vitamin D and obesity: current perspectives and future directions. Proc Nutr Soc 74, 115-124.

19. Savastano S, Barrea L, Savanelli MC, et al. (2017) Low vitamin D status and obesity: role of nutritionist. Rev Endocr Metab Disord 18, 215-225.

20. Vitseva OI, Tanriverdi K, Tchkonia TT, et al. (2008) Inducible tolllike receptor and NF- $\mathrm{Kb}$ regulatory pathway expression in human adipose tissue. Obesity 16, 932-937.

21. Chen GL, Wu JG, Variath M-T, et al. (2011) Timing of gene expression from different genetic systems in shaping leucine and isoleucine contents of rapeseed (Brassica napus L.) meal. J Genet 90, 459-468.

22. Filus A, Trzmiel A, Kuliczkowska-Płaksej J, et al. (2008) Relationship between vitamin D receptor BsmI and FokI polymorphisms and anthropometric and biochemical parameters describing metabolic syndrome. Aging Male 11, 134-139.

23. Ganji V, Milone C, Cody MM, et al. (2010) Serum vitamin D concentrations are related to depression in young adult US population: the Third National Health and Nutrition Examination Survey. Int Arch Med 3, 1-8.

24. May HT, Bair TL, Lappé DL, et al. (2010) Association of vitamin D levels with incident depression among a general cardiovascular population. Am Heart J 159, 1037-1043.

25. Hoang MT, DeFina LF, Willis BL, et al. (2011) Association between low serum 25-hydroxyvitamin D and depression in a large sample of healthy adults: the Cooper Center longitudinal study. Mayo Clin Proc 86, 1050-1055.

26. Umhau JC, George DT, Heaney RP, et al. (2013) Low vitamin D status and suicide: a case-control study of active duty military service members. PLOS ONE 8, e51543.

27. Havaux M, Ksas B, Szewczyk A, et al. (2009) Vitamin B6 deficient plants display increased sensitivity to high light and photo-oxidative stress. BMC Plant Biol 9, 130.

28. Eknoyan G (2008) Adolphe Quetelet (1796-1874)—the average man and indices of obesity. Nephrol Dial Transplant 23, 47-51.

29. Pusceddu I, Herrmann W, Kleber ME, et al. (2020) Subclinical inflammation, telomere shortening, homocysteine, vitamin B6, and mortality: the Ludwigshafen Risk and Cardiovascular Health Study. Eur J Nutr 59, 1399-1411. 
30. Mirzaei K, Hossein-Nezhad A, Keshavarz S, et al. (2014) Insulin resistance via modification of PGC1 $\alpha$ function identifying a possible preventive role of vitamin $\mathrm{D}$ analogues in chronic inflammatory state of obesity. A double blind clinical trial study. Minerva Med 105, 63-78.

31. Esfahani FH, Asghari G, Mirmiran P, et al. (2010) Reproducibility and relative validity of food group intake in a food frequency questionnaire developed for the Tehran Lipid and Glucose Study. J Epidemiol 20, 150-158.

32. Pfotenhauer KM \& Shubrook JH (2017) Vitamin D deficiency, its role in health and disease, and current supplementation recommendations. J Osteopath Med 117, 301-305.

33. Holick MF (2009) Vitamin D status: measurement, interpretation, and clinical application. Ann Epidemiol 19, 73-78.

34. Vatandost S, Jahani M, Afshari A, et al. (2018) Prevalence of vitamin D deficiency in Iran: a systematic review and meta-analysis. Nutr Health 24, 269-278.

35. Akbari S, Salehinasab F \& Alavi SER (2020) An ecological study on distribution of vitamin D level among pregnant women of Iran. J Paratbyr Dis 8, e04.

36. Dassprakash MV, Arun R, Abraham SK, et al. (2012) In vitro and in vivo evaluation of antioxidant and antigenotoxic potential of Punica granatum leaf extract. Pharm Biol 50, 1523-1530.

37. Brown TA, Chorpita BF, Korotitsch W, et al. (1997) Psychometric properties of the Depression Anxiety Stress Scales (DASS) in clinical samples. Behav Res Ther 35, 79-89.

38. Page AC, Hooke GR \& Morrison DL (2007) Psychometric properties of the Depression Anxiety Stress Scales (DASS) in depressed clinical samples. Br J Clin Psychol 46, 283-297.

39. Holick MF (2004) Vitamin D: importance in the prevention of cancers, type 1 diabetes, heart disease, and osteoporosis. Am J Clin Nutr 79, 362-371.

40. Holick MF (2004) Sunlight and vitamin D for bone health and prevention of autoimmune diseases, cancers, and cardiovascular disease. Am J Clin Nutr 80, 1678S-1688S.

41. Holick MF (2007) Vitamin D deficiency. N Engl J Med 357, 266-281.

42. Heaney RP, Dowell MS, Hale CA, et al. (2003) Calcium absorption varies within the reference range for serum 25-hydroxyvitamin D. J Am Coll Nutr 22, 142-146.
43. Tabrizi R, Moosazadeh M, Akbari M, et al. (2018) High prevalence of vitamin D deficiency among Iranian population: a systematic review and meta-analysis. Iran J Med Sci 43, 125.

44. Bikle DD, Gee E, Halloran B, et al. (1986) Assessment of the free fraction of 25-hydroxyvitamin $\mathrm{D}$ in serum and its regulation by albumin and the vitamin D-binding protein. J Clin Endocrinol Metab 63, 954-959.

45. Setayesh L, Amini A, Bagheri R, et al. (2021) Elevated plasma concentrations of vitamin D-binding protein are associated with lower high-density lipoprotein and higher fat mass index in overweight and obese women. Nutrients 13, 3223.

46. Coll AP, Farooqi IS, Challis BG, et al. (2004) Proopiomelanocortin and energy balance: insights from human and murine genetics. J Clin Endocrinol Metab 89, 2557-2562.

47. Linde JA, Jeffery RW, Levy R, et al. (2004) Binge eating disorder, weight control self-efficacy, and depression in overweight men and women. Int J Obes 28, 418-425.

48. Fairburn CG, Doll HA, Welch SL, et al. (1998) Risk factors for binge eating disorder: a community-based, case-control study. Arch Gen Psychiatry 55, 425-432.

49. Hotamisligil GS, Shargill NS \& Spiegelman BM (1993) Adipose expression of tumor necrosis factor-alpha: direct role in obesitylinked insulin resistance. Science 259, 87-91.

50. Rizzo SS, Neal S, Hughes Z, et al. (2012) Evidence for sustained elevation of IL-6 in the CNS as a key contributor of depressive-like phenotypes. Transl Psychiatry 2, e199-e199.

51. Money KM, Olah Z, Korade Z, et al. (2016) An altered peripheral IL6 response in major depressive disorder. Neurobiol Dis 89, 46-54.

52. Scott KM, McGee MA, Wells JE, et al. (2008) Obesity and mental disorders in the adult general population. I Psychosom Res 64, 97-105.

53. Mousa A, Naderpoor N, de Courten MP, et al. (2018) Vitamin D and symptoms of depression in overweight or obese adults: a crosssectional study and randomized placebo-controlled trial. I Steroid Biochem Mol Biol 177, 200-208.

54. Schaad KA, Bukhari AS, Brooks DI, et al. (2019) The relationship between vitamin $\mathrm{D}$ status and depression in a tactical athlete population. J Int Soc Sports Nutr 16, 1-9. 